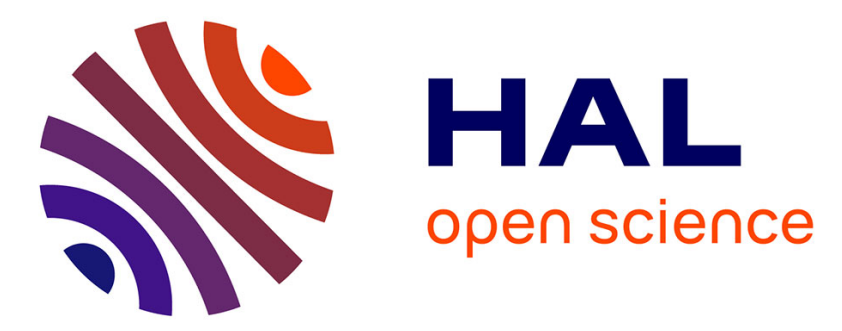

\title{
Convergent Reductive Depolymerization of Wood Lignin to Isolated Phenol Derivatives by Metal-Free Catalytic Hydrosilylation
}

\author{
Elias Feghali, Géraldine Carrot, Pierre Thuéry, Caroline Genre, Thibault
}

Cantat

\section{To cite this version:}

Elias Feghali, Géraldine Carrot, Pierre Thuéry, Caroline Genre, Thibault Cantat. Convergent Reductive Depolymerization of Wood Lignin to Isolated Phenol Derivatives by Metal-Free Catalytic Hydrosilylation. Energy \& Environmental Science, 2015, 8, pp.2734-2743. 10.1039/C5EE01304F . hal-01187816

\section{HAL Id: hal-01187816 https://hal.science/hal-01187816}

Submitted on 17 Nov 2015

HAL is a multi-disciplinary open access archive for the deposit and dissemination of scientific research documents, whether they are published or not. The documents may come from teaching and research institutions in France or abroad, or from public or private research centers.
L'archive ouverte pluridisciplinaire HAL, est destinée au dépôt et à la diffusion de documents scientifiques de niveau recherche, publiés ou non, émanant des établissements d'enseignement et de recherche français ou étrangers, des laboratoires publics ou privés. 


\section{Energy \& Environmental Science}

CrossMark \& clickfor updates

Cite this: Energy Environ. Sci., 2015, 8, 2734

Received 27th April 2015, Accepted 17th July 2015

DOI: $10.1039 / c 5 e e 01304 f$

www.rsc.org/ees

\section{Convergent reductive depolymerization of wood lignin to isolated phenol derivatives by metal-free catalytic hydrosilylation $\uparrow$}

\author{
Elias Feghali, Géraldine Carrot, Pierre Thuéry, Caroline Genre and Thibault Cantat*
}

The first examples of reductive depolymerization of lignin are reported under metal-free conditions. Using hydrosilanes as reductants and $\left.\mathrm{B}_{(} \mathrm{C}_{6} \mathrm{~F}_{5}\right)_{3}$ as a Lewis acid catalyst, wood lignin is efficiently converted to a narrow distribution of phenol derivatives at room temperature. A three-step methodology based on the selection of the wood species and the lignin extraction method followed by a convergent reductive depolymerization enables the production of four structurally defined aromatic compounds. The phenol products were successfully isolated in 7-24 wt\% yield from lignin and 0.5-2.4 wt\% yield from wood. The strategy is found to be robust and is applied to 15 different wood plants, including gymnosperm and angiosperm species. The efficiency of this novel methodology has been evaluated based on spectroscopic characterization of the lignin preparations and isolated yields of mono-aromatic products.

\section{Introduction}

The production of organic chemical commodities relies heavily on fossil resources as more than $95 \%$ of all organic chemicals currently derive from petrochemistry. The development of innovative synthetic methods utilizing renewable carbon feedstocks is thus attractive to improve the sustainability of this

CEA, IRAMIS, NIMBE, CNRS UMR 3685, 91191 Gif-sur-Yvette Cedex, France.

E-mail: thibault.cantat@cea.fr; Fax: +33 169086640

$\dagger$ Electronic supplementary information (ESI) available: Details of experimental procedures: lignin extraction methods and characterization, procedures of the catalytic depolymerization of lignin, the procedure of the hydrolysis of silylated aromatic compounds, synthesis of standards, characterization of new compounds as well as deuterium labeled products, HSQC analyses, GC-MS chromatograms, DEPT 135 spectra, SEC chromatograms, GC-MS calibration plots, theoretical yields and global efficiency calculations, tables of crystal data, atomic positions and displacement parameters, anisotropic displacement parameters, and bond lengths and bond angles in CIF format. CCDC 1061738 and 1061739. For ESI and crystallographic data in CIF or other electronic format see DOI: 10.1039/c5ee01304f industrial sector. ${ }^{1-7}$ In this context, $\mathrm{CO}_{2}$ is the subject of increased attention, and novel catalytic transformations have been unveiled over the last decade to take advantage of this carbon waste for the formation of formic acid, methanol and other chemicals. ${ }^{8-12}$ Nonetheless, it is already foreseeable that the scope of products available from $\mathrm{CO}_{2}$ will be mostly limited to $\mathrm{C}_{1}$-chemicals, complex compounds such as aromatics being more conveniently isolated from biomass waste, as an alternative carbon feedstock. Indeed, lignocellulose represents the main renewable source of aromatics and the depolymerization of lignin has been identified as a prominent challenge to produce bulk and fine chemicals in a sustainable manner. ${ }^{13-17}$ Lignin is a complex polymer biosynthesized from propenylphenol derivatives, namely $p$-coumaryl alcohol, coniferyl alcohol and sinapyl alcohol (Fig. 1). The oxidative radical polymerization of these three monolignols is responsible for the highly heterogenous structure of lignin, which is characterized by a variety of stable $\mathrm{C}-\mathrm{O}$ ether linkages and $\mathrm{C}-\mathrm{C}$ bonds between propenylphenol units. ${ }^{18,19}$ In most plants, the $\beta-\mathrm{O}-4$ linkage is predominant 


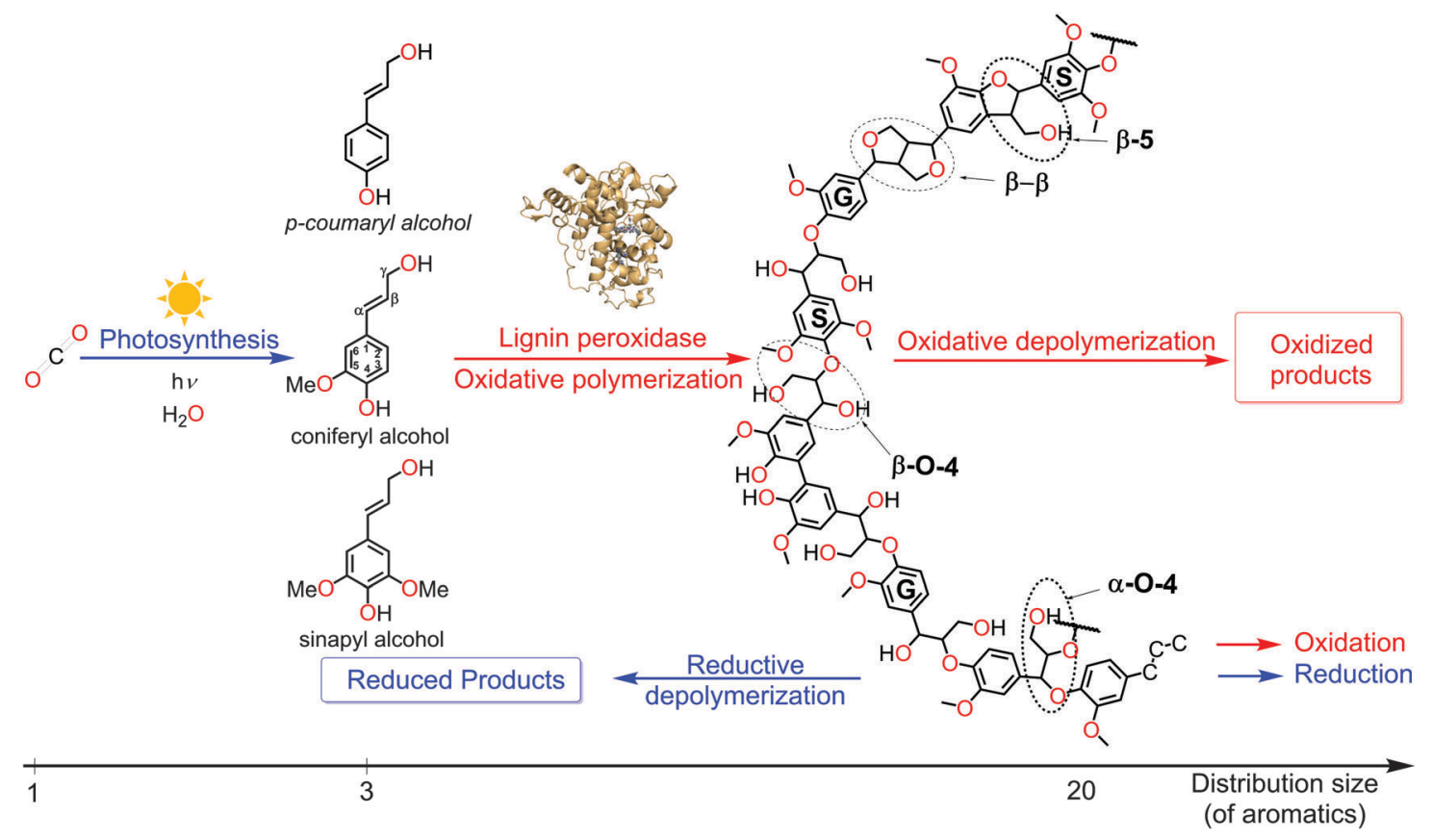

Fig. 1 Schematic representation of the distribution size of aromatic rings in monolignols, wood lignin and depolymerization products.

and this alkyl-aryl ether linkage results from the addition of the phenol group of one monolignol to the $\mathrm{C}_{\beta}$-atom on the propyl chain of the second monolignol. While the $\alpha-\mathrm{O}-4$ or $4-\mathrm{O}-5$ linkages also bear ether functionalities, the $\beta-\beta^{\prime}, 5-5^{\prime}$ and $\beta-1$ linkages connect two monolignols via a $\mathrm{C}-\mathrm{C}$ bond. ${ }^{20-22}$ The isolation of aromatic products from lignin is thus limited by the large distribution of aromatic rings, whose substitution patterns vary largely because of the low selectivity of lignin peroxidase polymerization and the presence of $\mathrm{H}, \mathrm{G}$ and $\mathrm{S}$ residues (Fig. 1). In addition, efficient depolymerization methods must cleave strong $\mathrm{C}-\mathrm{O}$ and/or $\mathrm{C}-\mathrm{C}$ bonds and tolerate a large variability of lignin samples derived from different types of plants. ${ }^{23-25}$

The depolymerization of lignin under oxidative conditions has been the focus of extensive efforts and recent success has demonstrated the potential of this approach. ${ }^{15,26,27}$ Markedly, Stahl and coworkers have developed an efficient oxidation method, under aerobic conditions, and the resulting oxidized lignin structure was depolymerized to low-molecular-mass aromatics in $>60 \mathrm{wt} \%$, using formic acid. ${ }^{28}$ Nevertheless, the oxidation strategies applied so far for lignin conversion lack chemoselectivity and yield complex mixtures with a wide distribution of aromatics, from which isolation of well-defined chemicals is an issue (Fig. 1).

In contrast, we hypothesized that reduction chemistry could promote the depolymerization of lignin while converging the products to a narrow distribution, from which aromatics can be easily isolated in a pure form. By replacing $\mathrm{C}-\mathrm{O}$ bonds with $\mathrm{C}-\mathrm{H}$ bonds, deoxygenation reactions are indeed expected to cleave ether groups to yield low-molecular-mass products with a distribution size close to that of the monolignols (1-3) (Fig. 1). This approach yet suffers from the lack of efficient catalysts able to reduce ether linkages. ${ }^{17,29,30}$ Interestingly, Westwood and coworkers explored the reduction of oxidized lignin models using stoichiometric amounts of zinc metal and the methodology, applied to organosolv lignin derived from birch sawdust, led to an isolable phenol product in $5 \mathrm{wt} \%$ per lignin wt. ${ }^{31} \mathrm{In}$ parallel, Wang, Xu and coworkers demonstrated that propylsyringol could be isolated from birch lignin, using a catalyst based on nickel on activated charcoal $(\mathrm{Ni} / \mathrm{C})$ and alcohols as reductants, under harsh conditions $\left(200{ }^{\circ} \mathrm{C}\right) .{ }^{32}$ Homogeneous catalysts, able to access the reactive sites in lignin, are thus attractive to promote the reductive depolymerization of lignin, under mild conditions and with enhanced chemoselectivity. ${ }^{33,34}$ While the reductive cleavage of lignin model compounds was developed using ruthenium ${ }^{35-39}$ and nickel-based ${ }^{40-42}$ catalysts, few examples of lignin depolymerization are known, mostly because of catalyst deactivation by the impurities present in the lignin matrix or by coordination to lignin. ${ }^{37,43}$

Herein, we disclose the first examples of the reductive depolymerization of lignin, extracted from softwood and hardwood, under metal-free conditions. Using hydrosilanes as reductants, propylphenol derivatives were successfully isolated in good $0.5-2.4 \mathrm{wt} \%$ yield from 15 different wood species (7 to $24 \mathrm{wt} \%$ from lignin) at room temperature.

\section{Results and discussion}

Hydrosilanes are mild reductants and their slightly polar $\mathrm{Si}-\mathrm{H}$ bonds can be activated at low temperature using molecular organometallic or organic catalysts to reduce $\mathrm{C}-\mathrm{O}$ bonds. ${ }^{44-46}$ For instance, $\mathrm{B}\left(\mathrm{C}_{6} \mathrm{~F}_{5}\right)_{3}$ is a potent Lewis acid, able to promote the reduction of a variety of carbonyl derivatives, including ketones, esters, amides and recently carbonates under mild conditions. ${ }^{45,47-55}$ 
Importantly, it can also serve as a catalyst in the hydrosilylation of alcohols and alkyl-ethers and we have recently shown that $\mathrm{B}\left(\mathrm{C}_{6} \mathrm{~F}_{5}\right)_{3}$ is able to cleave the $\beta-\mathrm{O}-4$ and $\alpha-\mathrm{O}-4$ linkages in simple lignin models, to yield 4-propylphenol derivatives. ${ }^{56}$ The reaction is chemoselective and diaryl-ethers and $\mathrm{C}-\mathrm{C}$ bonds are left untouched under these conditions. For example, treatment of 1 , a model of $\beta-\mathrm{O}-4$ linkage with a guaiacyl (G) residue, with 8 equiv. of $\mathrm{Et}_{3} \mathrm{SiH}$ leads to the formation of two catechol derivatives 2 and $3 G$, in the presence of $2 \mathrm{~mol} \% \mathrm{~B}\left(\mathrm{C}_{6} \mathrm{~F}_{5}\right)_{3}$ after $16 \mathrm{~h}$ at RT (Scheme 1). Interestingly, the primary silylether $\mathbf{4 G}$ can be obtained in $>80 \%$ yield using a default hydrosilane (7 equiv. of $\mathrm{Et}_{3} \mathrm{SiH}$ ) after $2 \mathrm{~h}$ at RT. The production of 2, 3G and 4G results from the reductive cleavage of the $\mathrm{O}-\mathrm{H}$ and $\mathrm{C}_{\mathrm{alkyl}}-\mathrm{O}$

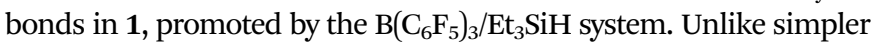
lignin models, ${ }^{56}$ no semi-pinacol rearrangement is observed for the guaiacyl residue and this fact was confirmed by the formation of D-labelled $\left[1,2-D_{2}\right]-4 G$ and $\left[1,2,3-D_{2}\right]-3 G$ from the reaction between 1 and $\mathrm{Et}_{3} \mathrm{SiD}$ (eqn (2) in Scheme 2 and ESI $\dagger$ ).

These results suggest that the depolymerization of lignin could be undertaken under hydrosilylation conditions via reductive cleavage of the $\beta-\mathrm{O}-4$ and $\alpha-\mathrm{O}-4$ linkages. To test this hypothesis, hardwood lignin was first extracted from chunks of black poplar using a Formacell organosolv process (vide infra), ${ }^{57,58}$ so as to eliminate the cellulose and hemicellulose parts of the wood cells. The resulting lignin preparation was then reacted with $276 \mathrm{wt} \%$ $\mathrm{Et}_{3} \mathrm{SiH}$ in $\mathrm{CH}_{2} \mathrm{Cl}_{2}$ at room temperature (RT) in the presence of $25 \mathrm{wt} \% \mathrm{~B}\left(\mathrm{C}_{6} \mathrm{~F}_{5}\right)_{3}$ (eqn (4) in Fig. 2). Based on simple estimations, these conditions correspond to a catalytic loading of $10 \mathrm{~mol} \%$ with 5 equiv. of $\mathrm{Et}_{3} \mathrm{SiH}$ with respect to the molar quantity of aromatic units in the lignin preparation (see ESI $\dagger$ ). Within $3 \mathrm{~h}$,

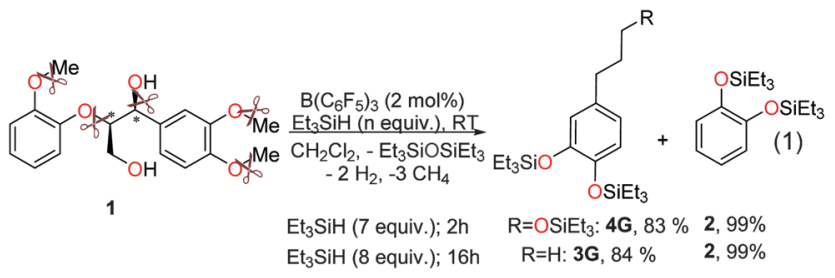

Scheme 1 Reductive cleavage of $\beta-\mathrm{O}-4$ model 1 using $\mathrm{Et}_{3} \mathrm{SiH}$ and the catalyst $\mathrm{B}\left(\mathrm{C}_{6} \mathrm{~F}_{5}\right)_{3}$.

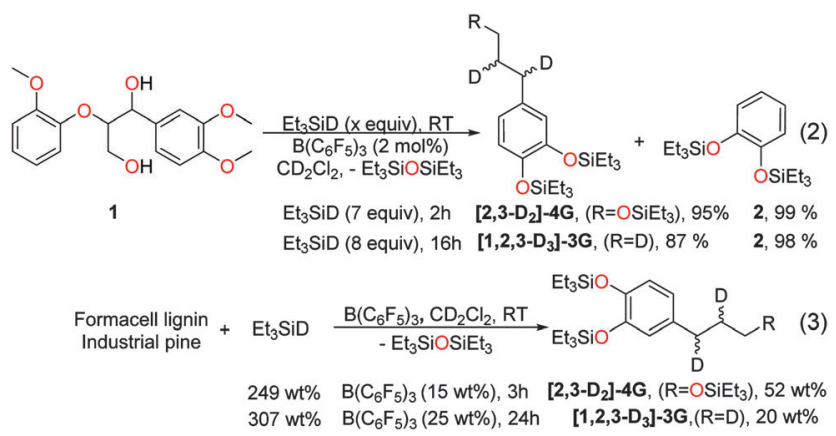

Scheme 2 Reductive cleavage of $\beta-\mathrm{O}-4$ model 1 using $\mathrm{Et}_{3} \mathrm{SiD}$ and the catalyst $\mathrm{B}\left(\mathrm{C}_{6} \mathrm{~F}_{5}\right)_{3}$ (eqn (2)). Reductive depolymerization of Formacell lignin derived from industrial pine lignin using $\mathrm{Et}_{3} \mathrm{SiD}$ and catalyst $\mathrm{B}\left(\mathrm{C}_{6} \mathrm{~F}_{5}\right)_{3}$ (eqn (3)).

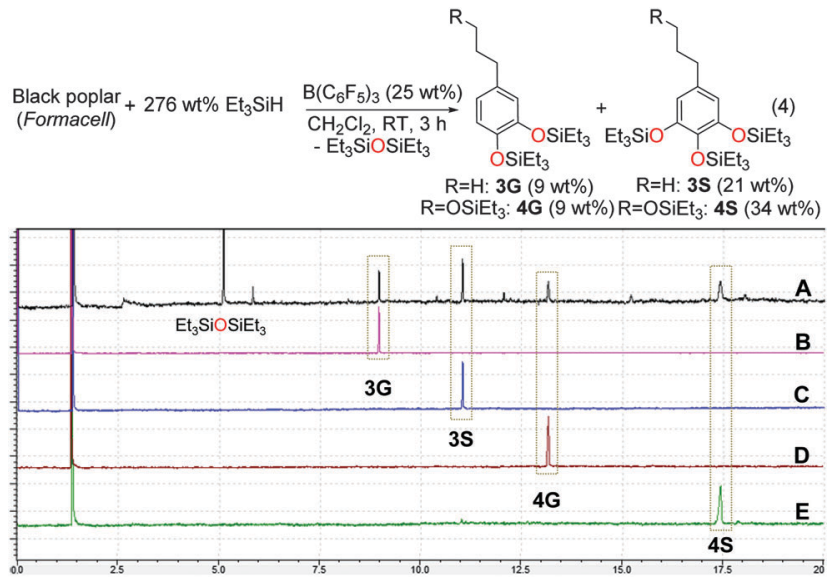

Fig. 2 Room temperature depolymerization of black poplar lignin with $\mathrm{B}\left(\mathrm{C}_{6} \mathrm{~F}_{5}\right)_{3} / \mathrm{Et}_{3} \mathrm{SiH}$ (eqn (4)). GC-MS chromatograms of the depolymerization residue of Formacell lignin derived from black poplar (A), and standards 3G (B), 3S (C), 4G (D) and 4S (E) synthesized from petrochemical raw materials.

the lignin material was completely dissolved in the reaction medium to afford a brown solution which was analysed by GC/MS. As depicted in Fig. 2, a small distribution of lowmolecular-mass products is obtained from the depolymerization of lignin. The formation of the siloxane by-product $\mathrm{Et}_{3} \mathrm{SiOSiEt}_{3}$ confirms the successful deoxygenation of the starting lignin material. The chromatogram also shows the formation of 4 different mono-aromatic products in 9-34 wt\% per lignin wt. Two of these products correspond to compounds 3G and 4G obtained from the hydrosilylation of model 1. Hardwood lignin generally features guaiacyl (G) and sinapyl (S) residues because its biosynthesis relies on coniferyl and sinapyl alcohols, with ratios varying with the plant type. ${ }^{18,19}$ As such, the sinapyl derivatives $3 S$ and $\mathbf{4 S}$ are also expected to be formed upon reductive depolymerization of black poplar lignin. Authentic samples of 3S and $4 S$ were synthesized from petrochemical raw materials (see ESI $\dagger$ ), thereby validating the formation of $3 \mathrm{~S}$ and $4 \mathrm{~S}$ upon reduction of lignin (Fig. 2). Although previous reductive depolymerization methods rely on the use of metal catalysts working at elevated temperatures $\left(>150{ }^{\circ} \mathrm{C}\right)$ or stoichiometric amounts of low valent metals as reductants, the formation of $3 \mathbf{G}, 3 \mathbf{3}, 4 \mathrm{G}$ and $4 \mathrm{~S}$ represents the first example of reductive depolymerization of lignin under metal-free conditions. It likely results from the reductive cleavage of the $\beta-\mathrm{O}-4$ and $\alpha-\mathrm{O}-4$ linkages, thereby supporting the possible transposition of the hydrosilylation of model 1 to the successful depolymerization of hardwood lignin. Interestingly, the formation of silylethers $\mathbf{4 G}$ and $\mathbf{4 S}$ indicates that the partial reduction of the $\beta-O-4$ and $\alpha-0-4$ linkages can be promoted in lignin, to preserve functional chemical groups. Quantitatively, $19 \mathrm{wt} \%$ of lignin is converted to the monoaromatics 3G, 3S, 4G and $\mathbf{4 S}$, while the remaining $81 \mathrm{wt} \%$ presumably afford poly-aromatic compounds because the $\beta-\beta^{\prime}$, $5-5^{\prime}, \beta-1$ and $\beta-5$ linkages can be modified, yet not cleaved by the $\mathrm{B}\left(\mathrm{C}_{6} \mathrm{~F}_{5}\right)_{3} / \mathrm{Et}_{3} \mathrm{SiH}$ system. These figures roughly represent a $25 \%$ molar yield of mono-aromatics. Notably, no product derived from the reduction of the $\mathrm{H}$ residue was detected. 
As hypothesized, the reductive depolymerization of lignin carried out in eqn (4) affords a small distribution of 4 monoaromatic products. The selective formation of 3G, 3S, 4G and $4 \mathrm{~S}$ was next sought after to avoid problematic separation procedures. As depicted in Fig. 3, different parameters govern the products composition. First, the wood species imposes the $\mathrm{H} / \mathrm{G} / \mathrm{S}$ ratio in the lignin matrix and four types have been unveiled based on the classification of lignin (based on a chemical approach), namely G, GS, HGS and HG. ${ }^{59}$ Previous studies have established that while gymnosperm plants primarily feature guaiacyl (G) residues, angiosperm species present a higher component of sinapyl (S) units. Additionally, the wood species could be advantageously selected so as to maximize the amount of lignin present in the lignocellulose matrix and the occurrence of reactive $\beta-\mathrm{O}-4$ and $\alpha-\mathrm{O}-4$ linkages (which averages $50-60 \%$ in wood lignin). Secondly, the extraction method utilized to separate lignin from cellulose and hemicellulose strongly influences the chemical properties of the lignin starting material, such as its solubility in different solvents, its degree of polymerization (DP) and the nature of the linkages. Changing the chemical properties of the lignin material strongly alter its behavior toward the depolymerization method. Finally, as derived from the reaction chemistry of the lignin models, the depolymerization step itself controls the reduction of lignin and longer reaction times in the presence of an excess of hydrosilane should favor the formation of reduced 4-propylphenol derivatives $\mathbf{3 G}$ and $\mathbf{3 S}$ over $\mathbf{4 G}$ and $\mathbf{4 S}$. Based on an integration of these different parameters, the selective formation of $\mathbf{3 G}$ was first explored (Fig. 4).

Because softwood lignin extracted from gymnosperm species features a prominent portion of $\mathrm{G}$ residues, ${ }^{60,61}$ synthesis of $3 \mathbf{G}$ was attempted with Nordmann fir, Norway spruce, parasol pine, Lebanon cedar and Pacific red cedar. Several pretreatment methods have been developed to separate lignin, hemicellulose and cellulose in wood. The sulfite and Kraft processes target the production of high quality cellulose for the pulp and paper industry and the resulting Kraft $\operatorname{lignin}^{62}$ and lignosulfonates ${ }^{63}$ are generated as by-products. Valorization of these lignin preparations is thus attractive. Nevertheless, because lignin is obtained under harsh and/or acidic conditions, the resulting polymeric structure is significantly altered from native lignin and features an increased proportion of $\mathrm{C}-\mathrm{C}$ based linkages. ${ }^{64}$ As a result, using Kraft or sulfite lignin, only negligible amounts of 3G were obtained in the presence of $305 \mathrm{wt} \% \mathrm{Et}_{3} \mathrm{SiH}$ and

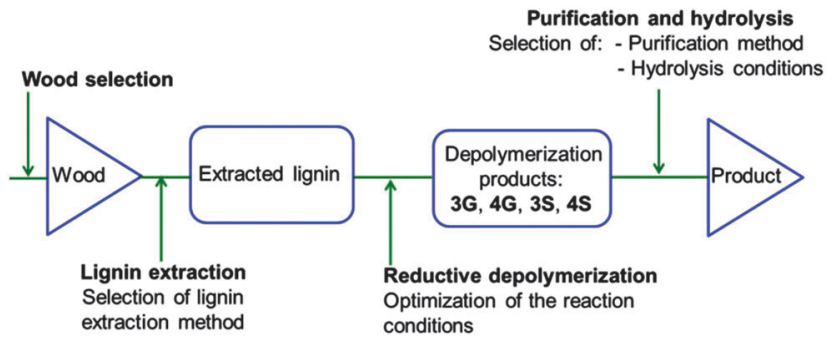

Fig. 3 Convergent reductive depolymerization strategy enabling the formation of pure mono-aromatic products from wood.

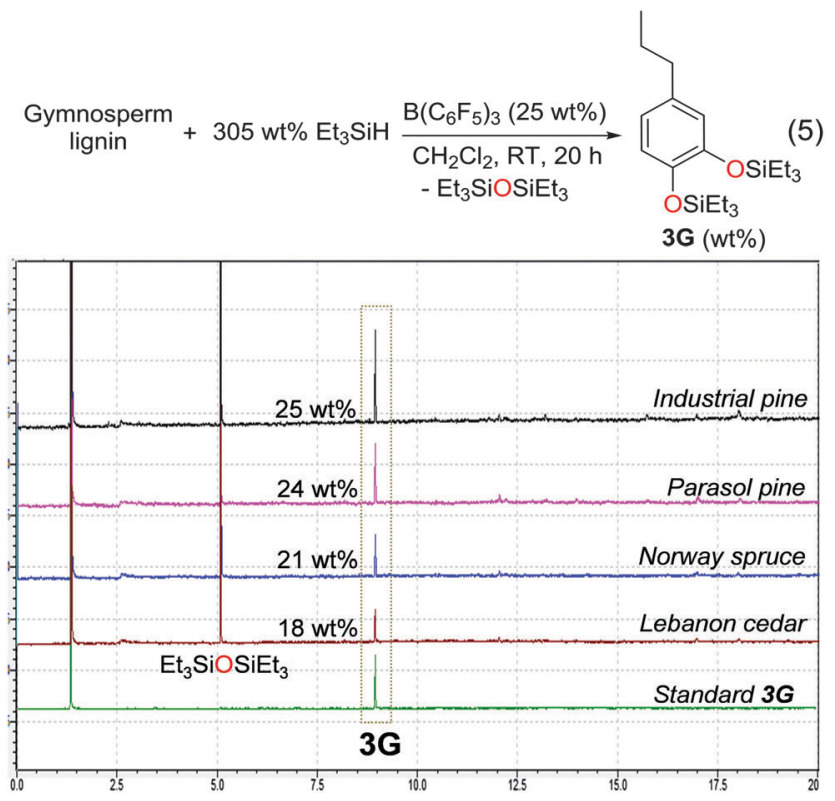

Fig. 4 Room temperature depolymerization of gymnosperm lignin with $\mathrm{B}\left(\mathrm{C}_{6} \mathrm{~F}_{5}\right)_{3} / \mathrm{Et}_{3} \mathrm{SiH}$ to $3 \mathrm{G}$ (eqn (5)). GC-MS chromatograms of the depolymerization residue of Formacell lignin derived from industrial pine, parasol pine, Norway spruce, Lebanon cedar and standard 3G synthesized from petrochemical raw materials.

$25 \mathrm{wt} \% \mathrm{~B}\left(\mathrm{C}_{6} \mathrm{~F}_{5}\right)_{3} .{ }^{65}$ In contrast, extraction methods utilizing organic solvents (organosolv treatment) operate under milder conditions and are known to preserve the native structure of lignin by reducing $\mathrm{C}-\mathrm{C}$ coupling reactions. Using Formacell $\operatorname{lignin}^{57,58}$ extracted from Norway spruce (Picea abies) with formic acid, acetic acid and water, $3 \mathbf{G}$ is formed in $21 \mathrm{wt} \%$ yield after $20 \mathrm{~h}$ at $\mathrm{RT}$ in the presence of $305 \mathrm{wt} \% \mathrm{Et}_{3} \mathrm{SiH}$ and $25 \mathrm{wt} \%$ $\mathrm{B}\left(\mathrm{C}_{6} \mathrm{~F}_{5}\right)_{3}$. Similarly, other wood species tested under these conditions afforded 3G in 18-25 wt\% yield (Fig. 4). Size exclusion chromatography (SEC) confirmed that organosolv lignin only contains a small proportion of low-molecular-mass fragments (Fig. 5). Notably, the efficiency of the reductive depolymerization is demonstrated by SEC analysis of the crude solution after hydrosilylation of lignin, which shows the conversion of longer chain fragments to di- and tri-aromatics, together with the formation of a narrow distribution of mono-aromatic products. Additionally, two dimensional HSQC NMR spectroscopy revealed that the $\beta-O-4$ linkages (only $G$ residues) present in the lignin preparation are quantitatively cleaved upon depolymerization, leading to the formation of $\mathbf{3 G}$ (see ESI $\dagger$ ). Interestingly, no re-polymerization was observed, likely because the mild reaction conditions (RT, $P=1 \mathrm{~atm}$ ) prevent $\mathrm{C}-\mathrm{C}$ coupling reactions of the lignin residues.

Additionally, deuterated [1,2,3-- $\left.\mathbf{D}_{3}\right]-3 \mathrm{G}$ is obtained when $\mathrm{Et}_{3} \mathrm{SiD}$ is used in place of $\mathrm{Et}_{3} \mathrm{SiH}$ in the depolymerization of industrial pine lignin, showing that the mechanism responsible for the reductive cleavage of $\beta$-O- 4 model 1 can be confidently transposed to lignin (eqn (3) in Scheme 2). ${ }^{56}$ The extraction method has a notable influence on the productivity and the selectivity. While $3 \mathbf{G}$ is obtained in $25 \mathrm{wt} \%$ yield from industrial pine 


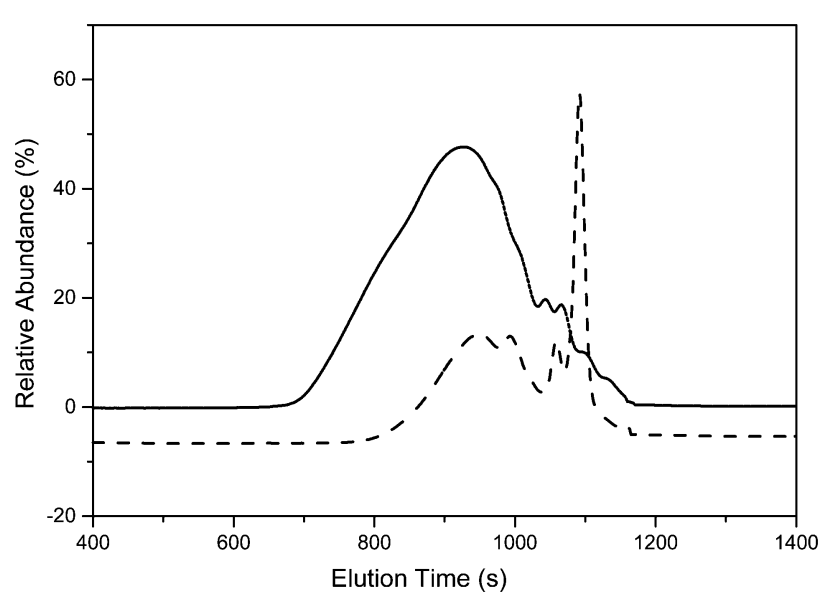

Fig. 5 SEC chromatograms of parasol pine lignin extracted using the Formacell process (dot line); the crude mixture after reductive depolymerization with $305 \mathrm{wt} \% \mathrm{Et}_{3} \mathrm{SiH}$ and $25 \mathrm{wt} \% \mathrm{~B}\left(\mathrm{C}_{6} \mathrm{~F}_{5}\right)_{3}\left(20 \mathrm{~h}\right.$ at $\mathrm{RT}$, in $\left.\mathrm{CH}_{2} \mathrm{Cl}_{2}\right)$ (dash line). According to Fig. 5, the number-average molecular weight $M_{\mathrm{n}}$ decreases from $952 \mathrm{~g} \mathrm{~mol}^{-1}$ to $268 \mathrm{~g} \mathrm{~mol}^{-1}$ after depolymerization.

sawdust using the Formacell method, the corresponding yield drops to 18, 12 and $4 \mathrm{wt} \%$ when ethanol (EOL), methanol (MOL) or acetone (AOL) organosolv lignin is used, and other unidentified volatiles were detected as side-products. Interestingly, when Kraft lignin is re-extracted using the Formacell process, the resulting lignin preparation is not depolymerized with the $\mathrm{B}\left(\mathrm{C}_{6} \mathrm{~F}_{5}\right)_{3} / \mathrm{Et}_{3} \mathrm{SiH}$ system, confirming that the Kraft process strongly modifies the structure of lignin. The depolymerization of Formacell lignin with PMHS (polymethylhydrosiloxane) and TMDS (tetramethyldisiloxane) hydrosilanes led to the formation of a gel in $\mathrm{CH}_{2} \mathrm{Cl}_{2}$. Nevertheless, a disilylated propylcatechol product (analogous to 3G) is successfully formed with TMDS when benzene is used as a solvent, albeit with a modest $\sim 9 \mathrm{wt} \%$ yield (compared to 25 wt\% with $\mathrm{Et}_{3} \mathrm{SiH}$ ) (see $\mathrm{ESI} \dagger$ ).

As depicted in Fig. 4, 3G is the main low-molecular-mass product obtained upon depolymerization of softwood lignin under the applied conditions and 4G, 3S and $4 \mathbf{S}$ were not detected. Facilitated by the convergence, the purification of the crude mixture by flash chromatography enables the isolation of 3G as a pure product in $19 \mathrm{wt} \%$ per lignin wt. A boiling point of $230{ }^{\circ} \mathrm{C}$ was measured for $3 \mathbf{G}$ (at 760 Torr) and it could also be recovered by distillation. From a practical viewpoint, this method has the advantage of utilizing less solvents for a larger scale synthesis of $\mathbf{3 G}$. Hydrolysis of $\mathbf{3 G}$ with $\left[n-\mathrm{Bu}_{4} \mathrm{~N}^{+}, \mathrm{F}^{-}\right]$in THF affords valuable 4-propylbenzene-1,2-diol $\left(\mathbf{3 G}^{\prime}\right)$ in $84 \%$ yield from 3G and 3-10 wt\% yield from lignin, depending on the wood source and the nature of the pre-treatment (Scheme 3 and Table S3, ESI $\dagger$ ). In comparison, Westwood et al. were able to isolate 3-hydroxy-1-(4-hydroxy-3,5-dimethoxyphenyl)propan1-one in $5 \mathrm{wt} \%$ by depolymerization of oxidized lignin, using a stoichiometric quantity of $\operatorname{zinc}(0)$ metal. ${ }^{31} \mathbf{3 G}^{\prime}$ is a common skeleton in a wide range of useful chemicals and is indeed the starting material for the synthesis of quinone methides, which are currently studied due to their anti-oxidant and cytotoxic properties. $^{66}$ Moreover, 3G' ${ }^{\prime}$ has been utilized as an intermediate for the formation of benzodioxole derivatives, used as
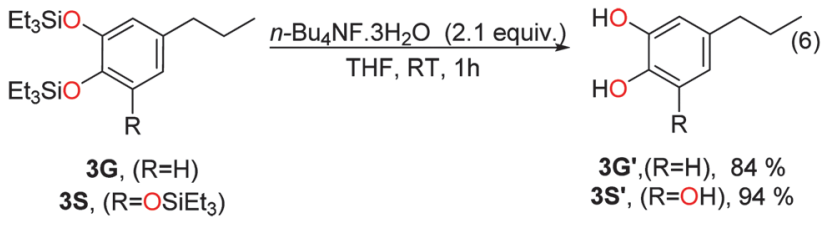

$3 G^{\prime},(\mathrm{R}=\mathrm{H}), 84 \%$ 3S', $(\mathrm{R}=\mathrm{OH}), 94 \%$

Scheme 3 Hydrolysis reaction of $\mathbf{3 G}$ and $\mathbf{3 S}$ to $\mathbf{3} \mathbf{G}^{\prime}$ and $\mathbf{3 \mathbf { S } ^ { \prime }}$ respectively using $\left[n-\mathrm{Bu}_{4} \mathrm{~N}^{+}, \mathrm{F}^{-}\right]$in THF (eqn (6)).

perfume ingredients, ${ }^{67}$ as well as the synthesis of liquid crystals ${ }^{68}$ and fuels. ${ }^{69}$

The production of $\mathbf{3 G}$ (and $\mathbf{3 G}^{\prime}$ ) from lignin results from the ability of the $\mathrm{B}\left(\mathrm{C}_{6} \mathrm{~F}_{5}\right)_{3} / \mathrm{Et}_{3} \mathrm{SiH}$ system to (i) cleave the $\beta$-O- 4 and $\alpha-\mathrm{O}-4$ linkages and (ii) converge the resulting mono-aromatics by reductive deoxygenation of their propyl-chain. Importantly, the loss of chemical functionalities associated with reductive deoxygenation has been identified as a drawback in the depolymerization of lignin using reductants. ${ }^{32,70,71}$ Nonetheless, the formation of $\mathbf{4 G}$ suggests that this issue could be tackled using the present hydrosilylation approach, which is able to balance the reactivity of the different $\mathrm{C}-\mathrm{O}$ bonds in lignin. Based on the reactivity of lignin models with the hydrosilane- $B\left(\mathrm{C}_{6} \mathrm{~F}_{5}\right)_{3}$ system, the depolymerization of Formacell pine lignin was carried out with $247 \mathrm{wt} \% \mathrm{Et}_{3} \mathrm{SiH}$ and $15 \mathrm{wt} \% \mathrm{~B}\left(\mathrm{C}_{6} \mathrm{~F}_{5}\right)_{3}$. After $3 \mathrm{~h}$ at RT, GC/MS analysis of the crude mixture revealed the selective formation of $\mathbf{4 G}$ as the only mono-aromatic product, in $52 \mathrm{wt} \%$ yield (Fig. 6).

Replacing industrial pine with parasol pine, Lebanon cedar or Norway spruce, 4G was obtained in 50, 42 and $34 \mathrm{wt} \%$ yields, respectively. As expected, $\mathbf{4 G}$ is an intermediate in the formation of $3 \mathrm{G}$ and monitoring the reduction of lignin with $305 \mathrm{wt} \%$ $\mathrm{Et}_{3} \mathrm{SiH}$ and $25 \mathrm{wt} \% \mathrm{~B}\left(\mathrm{C}_{6} \mathrm{~F}_{5}\right)_{3}$ over time reveals the formation of 4G and its subsequent reduction to 3G. These results show that the chemoselectivity of the $\mathrm{B}\left(\mathrm{C}_{6} \mathrm{~F}_{5}\right)_{3} / \mathrm{Et}_{3} \mathrm{SiH}$ system enables the convergent formation of $\mathbf{4 G}$ while maintaining a reactive functional group. Notably, hydrolysis of $\mathbf{4 G}$ affords $\mathbf{4 G}^{\prime}$ in $84 \%$ yield. $\mathbf{4 G}^{\prime}$ formally results from the hydroxylation of a terminal $\mathrm{C}-\mathrm{H}$ bond on the propyl chain of $\mathbf{3 G}^{\prime}$ and, hence, offers extended reactivity patterns for future utilization.

3S and $\mathbf{4 S}$ are sinapyl analogues of $\mathbf{3 G}$ and $\mathbf{4 G}$, respectively. Their selective formation was thus investigated using the convergent reductive depolymerization method described for 3G and 4G. Angiosperm species are of the GS and HGS types and can thus contain a large portion of sinapyl residues. For example, common beech (Fagus sylvatica) and blue gum (Eucalyptus globulus) present $>75 \% \mathrm{~S}$ residues and about $20 \%$ and $5 \% \mathrm{G}$ and $\mathrm{H}$ residues, respectively. ${ }^{72,73}$ Formacell lignin samples extracted from black poplar, common beech, silver birch, evergreen oak, date palm, hybrid plane and river red gum were subjected to depolymerization with the hydrosilane- $\mathrm{B}\left(\mathrm{C}_{6} \mathrm{~F}_{5}\right)_{3}$ system. Addition

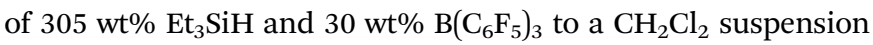
of lignin from evergreen oak resulted in the complete dissolution of the solid materials after $20 \mathrm{~h}$ at RT and GC/MS analysis of the solution confirms the formation of $\mathbf{3 S}$ as the major lowmolecular-mass product in $45 \mathrm{wt} \%$ yield. $3 \mathbf{G}$ is also formed as a side product under these conditions, reflecting the natural 

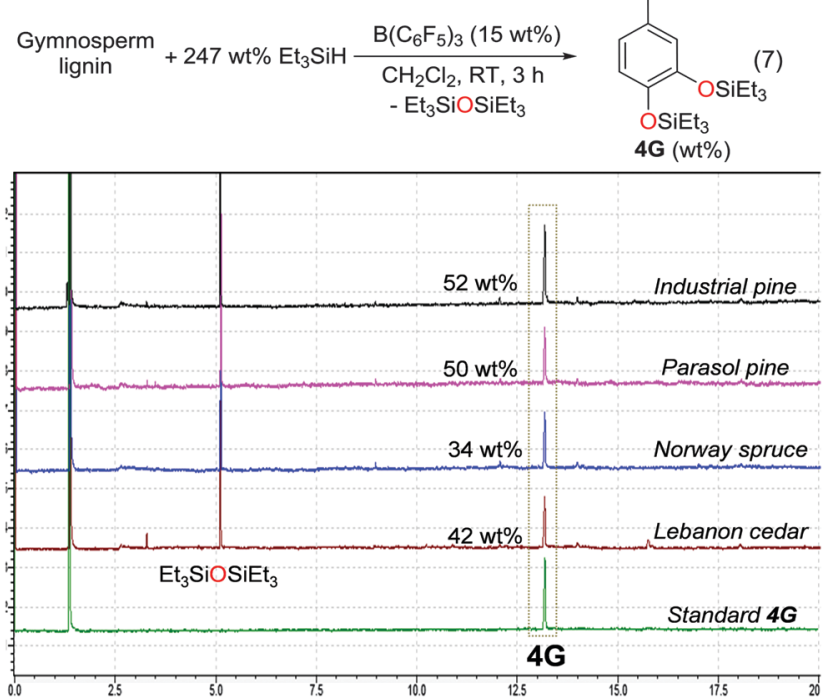

Fig. 6 Room temperature depolymerization of gymnosperm lignin with $\mathrm{B}\left(\mathrm{C}_{6} \mathrm{~F}_{5}\right)_{3} / \mathrm{Et}_{3} \mathrm{SiH}$ to $4 \mathrm{G}$ (eqn (7)). GC-MS chromatograms of the depolymerization residue of Formacell lignin from industrial pine, parasol pine, Norway spruce, Lebanon cedar and standard 4G synthesized from petrochemical raw materials.

coexistence of $\mathrm{S}$ and $\mathrm{G}$ residues in native lignocellulose. HSQC analysis of a sample of Formacell lignin derived from evergreen oak indeed revealed the presence of $\mathrm{S}$ and $\mathrm{G}$ residues linked mainly through the $\beta$-O-4 linkage. As expected, the absence of $\beta-\mathrm{O}-4$ signals and the presence of signals for $\mathbf{3 G}$ and $\mathbf{3 S}$ were observed after depolymerization (see ESI $\dagger$ ). Depending on the wood species, $3 \mathrm{~S}$ was successfully obtained in 23 to $51 \mathrm{wt} \%$ yield and the best results were obtained for evergreen oak and hybrid plane wood, which afforded selectively $3 \mathrm{~S}$ in 45 and $51 \mathrm{wt} \%$ yields, respectively, with relatively low amounts of 3G (Scheme 4). Hydrolysis of $3 \mathbf{S}$ ( $\mathrm{bp}=300 \pm 10{ }^{\circ} \mathrm{C}$ at 760 Torr) affords $3 \mathbf{S}^{\prime}$ in $87 \%$ yield. $3 \mathbf{S}^{\prime}$ is a crystalline material and its structure was determined by single-crystal X-ray diffraction (Fig. 7). All the hydroxyl groups are involved in intermolecular hydrogen bonding, which gives rise to the formation of sheets parallel to the (010) plane. While the hydroxyl groups are located inside the sheets, the alkyl chains protrude outside, thus defining hydrophobic inter-layer spaces (see Fig. S13 in the ESI $\dagger$ ). The crystallinity of $3 \mathbf{S}^{\prime}$ can be advantageously utilized to separate $\mathbf{3} \mathbf{S}^{\prime}$ from the oily $\mathbf{3} \mathbf{G}^{\prime}$ product, without the need for an expensive chromatographic method. In fact, $\mathbf{3} \mathbf{S}^{\prime}$ can be isolated in $94 \%$ yield by recrystallization from a hot $\mathrm{CHCl}_{3}$ solution of $3 \mathbf{S}^{\prime} / \mathbf{3} \mathbf{G}^{\prime}(3: 1)$.

Importantly, the more functionalized $\mathbf{4 S}$ product can also be isolated, by controlling the experimental conditions for the hydrosilylative depolymerization of hardwood lignin. As shown in Scheme 5, Formacell lignin affords $\mathbf{4 S}$ in $50-126 \mathrm{wt} \%$ yield, after $3 \mathrm{~h}$ at RT in the presence of a limited quantity of hydrosilanes (254 wt $\left.\% \mathrm{Et}_{3} \mathrm{SiH}\right)$ and a low catalyst loading of $20 \mathrm{wt} \%$. Hydrolysis of $\mathbf{4 S}$ could be carried out using $\left[n-\mathrm{Bu}_{4} \mathrm{~N}^{+}, \mathrm{F}^{-}\right]$in THF, to afford $\mathbf{4 \mathbf { S } ^ { \prime }}$ in $82 \%$ yield (see ESI†).

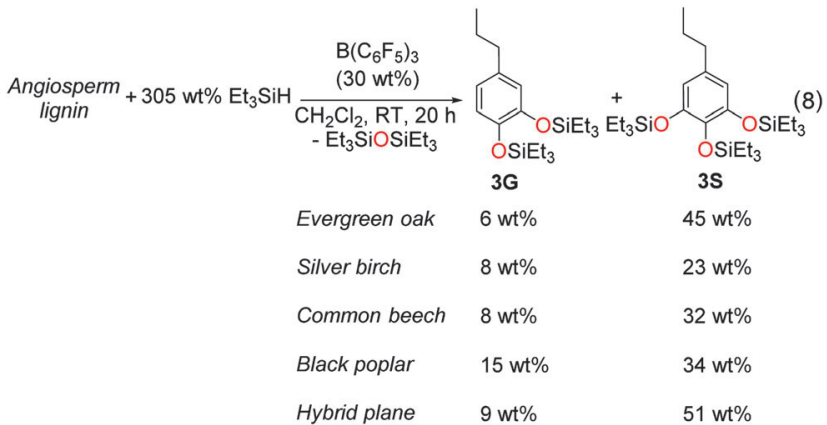

Scheme 4 Room temperature depolymerization of Formacell lignin (derived from angiosperm wood) to $3 \mathrm{~S}$, using $\mathrm{B}\left(\mathrm{C}_{6} \mathrm{~F}_{5}\right)_{3} / \mathrm{Et}_{3} \mathrm{SiH}$.

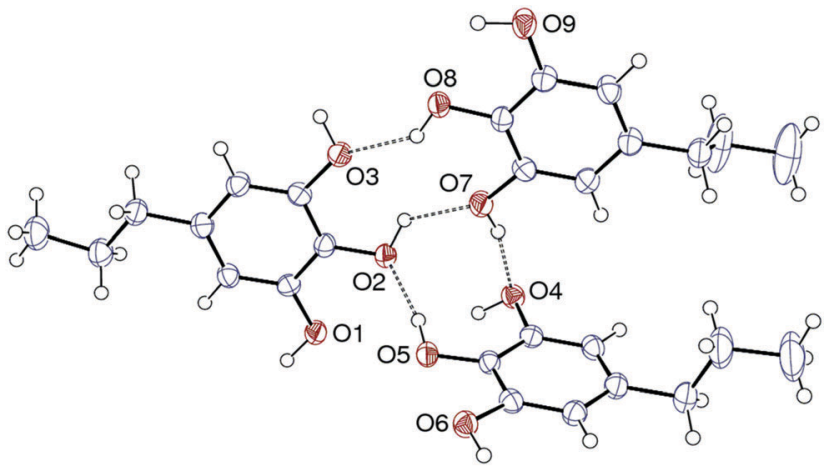

Fig. 7 View of the three crystallographically independent molecules in the crystal structure of $\mathbf{3 \mathbf { S } ^ { \prime }}$, with part of the hydrogen bonding network. Displacement ellipsoids are drawn at the $50 \%$ probability level.

Overall, isolation of compounds $3 \mathbf{G}, \mathbf{4 G}, 3 \mathbf{S}$ and $\mathbf{4 S}$ was performed on a large range of 15 different wood species and the respective yields and depolymerization conditions are summarized in Table 1. The hydrolyzed products can be isolated in high yield, so that $\mathbf{3} \mathbf{G}^{\prime}, \mathbf{4} \mathbf{G}^{\prime}, \mathbf{3} \mathbf{S}^{\prime}$ and $\mathbf{4} \mathbf{S}^{\prime}$ are formed selectively in 9-12 wt\% from the pre-treated lignin material and $0.5-2.4 \mathrm{wt} \%$ from wood. In comparison, vanillin is today the only industrial mono-aromatic chemical obtained from lignin and it is produced since 1993 by the Norwegian company Borregaard by oxidation of lignosulfonate using a copper catalyst. Starting from 1 ton of wood, an average of $3 \mathrm{~kg}$ of vanillin is obtained

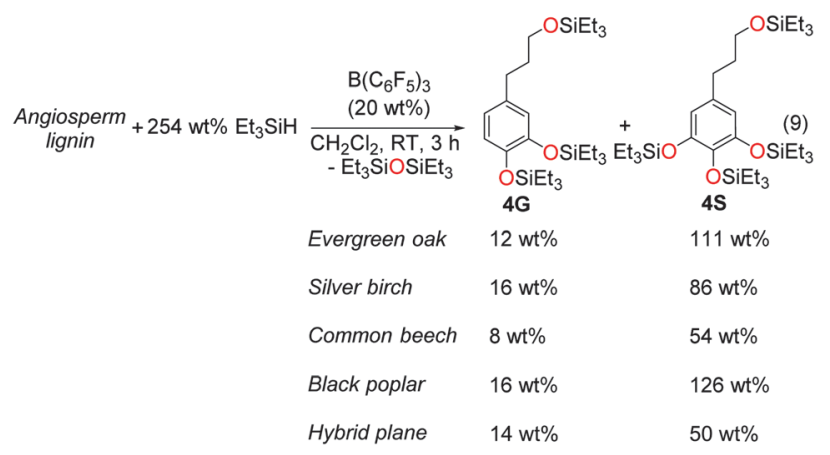

Scheme 5 Room temperature depolymerization of Formacell lignin (derived from angiosperm wood) to $4 \mathrm{~S}$, uisng $\mathrm{B}\left(\mathrm{C}_{6} \mathrm{~F}_{5}\right)_{3} / \mathrm{Et}_{3} \mathrm{SiH}$. 
with a global efficiency of $0.3 \mathrm{wt} \% .^{13,74}$ In order to address the efficiency of the present integrated depolymerization strategy, we calculated the maximum theoretical yields of $\mathbf{3} \mathbf{G}^{\prime}, \mathbf{4 G}^{\prime}, \mathbf{3} \mathbf{S}^{\prime}$ and $\mathbf{4} \mathbf{S}^{\prime}$. Three successive steps are involved in the production of these compounds, namely (i) the extraction of lignin from wood sawdust or wood chunks using an organosolv process, (ii) the reductive depolymerization of the lignin preparation and (iii) the isolation, hydrolysis and purification of the endproduct (Fig. 3). As depicted in Fig. 6, the amount of lignin extracted using the Formacell process varies with the wood species from 7 to $20 \mathrm{wt} \%$ yield and the efficiency of this step is in general greater for angiosperm species. This is likely due to the larger content of $\alpha-\mathrm{O}-4$ linkages in hardwood, these linkages being more easily cleavable by the lignin extraction method. ${ }^{75}$ Since the lignin content in the selected wood samples averages $20-30 \mathrm{wt} \%$, the efficiency of the organosolv process is close to $40 \%$.

Evaluation of the efficiency of the depolymerization step requires a finer description of the lignin preparation. Indeed, the theoretical yield for the formation of $\mathbf{3 G}$ (for example) depends on the proportion of $\beta-O-4$ and $\alpha$-O- 4 linkages, cleavable with the hydrosilane- $B\left(\mathrm{C}_{6} \mathrm{~F}_{5}\right)_{3}$ system, and the degree of polymerization in the lignin starting material. While hardwood contains about $60 \% \beta-\mathrm{O}-4$ and $6-8 \% \alpha-\mathrm{O}-4$ linkages, the proportions of cleavable ether linkages is somewhat lower in softwood lignin (46\% $\beta-\mathrm{O}-4$ and $6-8 \% \alpha-\mathrm{O}-4) .{ }^{13}$ Assuming that lignin is a linear polymer containing about $P=60 \% \beta-\mathrm{O}-4$ and $\alpha$-O-4 linkages (cleavable linkages), an infinite lignin chain will afford a maximum of $P^{2}=36 \%$ mono-aromatics. The successful formation of a C9 unit indeed necessitates that two consecutive cleavable linkages are located in the polymer chain. Because the depolymerization step is unreactive towards aryl-ethers and $\mathrm{C}-\mathrm{C}$ bonds, phenol units linked through $4-\mathrm{O}-5, \beta-\beta^{\prime}, 5-5^{\prime}$ and $\beta-1$ bonds yield dimers or heavier poly-aromatics. For a finite lignin chain featuring $N$ monolignols, the theoretical yield $\tau(N)$ follows the expression (see ESI $\dagger$ ):

$$
\tau(N)=\frac{(N-2) \times 0.6^{2}+2 \times 0.6}{N} \times 100
$$

As depicted in Fig. 8, $\tau(N)$ decreases rapidly from $60 \%(N=2)$ to its $36 \%$ asymptote with the increase in $N$ values, as the number of chain-ends decreases with longer chains. Size exclusion chromatography (SEC) was thus utilized to estimate the degree of polymerization (DP) of Formacell lignin in the studied samples

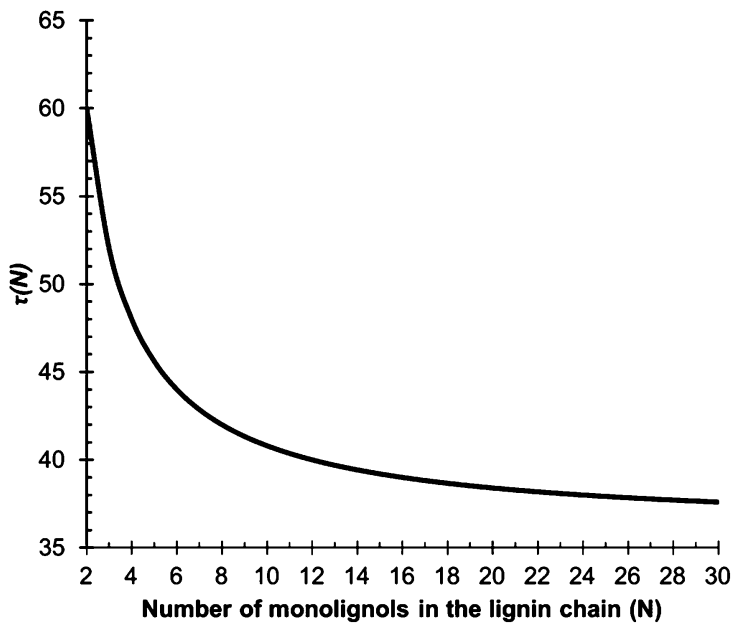

Fig. 8 Variation of the maximum molar yield of mono-aromatics $\tau(N)$ as a function of the polymer chain length $(N)$, for the reductive depolymerization of lignin by cleavage of $\beta-O-4$ and $\alpha-O-4$ linkages.

(see the ESI $\dagger$ and Fig. 5). The lignin samples extracted using the Formacell or ethanol method from parasol pine or evergreen oak are partially soluble in THF and from SEC, number-average molecular weights $\left(M_{\mathrm{n}}\right)$ of lignin were calculated ranging from 669 to $1099 \mathrm{~g} \mathrm{~mol}^{-1}$, with a polydispersity $\left(M_{\mathrm{w}} / M_{\mathrm{n}}\right)$ between 1.35 and 1.8 (Fig. 5 and ESI $\dagger$ ). These results suggest a relatively narrow molecular weight distribution with a DP of $5 \pm 1$. Accordingly, a maximum of $\tau(5)=46 \%$ phenol units can be extracted by hydrosilylative depolymerization of lignin, while 9-35 mol\% yields were measured experimentally for the conversion of lignin to $\mathbf{3 G}, \mathbf{4 G}, \mathbf{3 S}$ and $\mathbf{4 S}$. This calculation in fact shows that depolymerization with the hydrosilane- $\mathrm{B}\left(\mathrm{C}_{6} \mathrm{~F}_{5}\right)_{3}$ system is rather efficient, with an efficiency of 28 to $85 \%$ depending on the wood source and the targeted product. Finally, isolation and purification of $\mathbf{3} \mathbf{G}^{\prime}, \mathbf{4} \mathbf{G}^{\prime}, \mathbf{3} \mathbf{S}^{\prime}$ and $\mathbf{4} \mathbf{S}^{\prime}$ products from their silylated analogues were achieved experimentally in $>82 \%$ yield and efficiency (see ESI $\dagger$ ). Overall, pure $\mathbf{3} \mathbf{G}^{\prime}, \mathbf{4 G}^{\prime}, \mathbf{3 \mathbf { S } ^ { \prime }}$ and $\mathbf{4 S ^ { \prime }}$ were isolated in $0.7-3.0 \mathrm{wt} \%$ yield from wood in three steps. Theoretically, the maximum yield for the extraction of these products is $9 \pm 1 \mathrm{wt} \%$, revealing that the present three-step procedure exhibits an efficiency of 6-26\% (Table 2). Unsurprisingly, the isolation and purification step presents the best efficiency as it involves classical and robust separation techniques, at the

Table 1 Catalytic conversion of angiosperm and gymnosperm lignin to 3G, 4G, 3S and 4S. Isolated yields are given in brackets

\begin{tabular}{|c|c|c|c|c|c|c|}
\hline & Species & $\begin{array}{l}\mathrm{Et}_{3} \mathrm{SiH} \\
(\mathrm{wt} \%)\end{array}$ & $\begin{array}{l}\mathrm{B}\left(\mathrm{C}_{6} \mathrm{~F}_{5}\right)_{3} \\
(\mathrm{wt} \%)\end{array}$ & $\begin{array}{l}\text { Reaction } \\
\text { time }(\mathrm{h})\end{array}$ & $\begin{array}{l}\text { Isolated } \\
\text { product }\end{array}$ & $\begin{array}{l}\text { Yield } \\
\text { (wt\% per lignin wt) }\end{array}$ \\
\hline \multirow{4}{*}{ 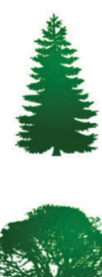 } & Gymnosperm wood lignin from: industrial pine; & 247 & 15 & 3 & 4G & $34-52$ \\
\hline & Norway spruce; Lebanon cedar; Pinus pinea & 305 & 25 & 20 & 3G & $18-25(19)$ \\
\hline & Angiosperm wood lignin from: evergreen oak; & 254 & 20 & 3 & $4 S$ & $50-126(90)$ \\
\hline & silver birch, common beech, black poplar and hybrid plane & 305 & 30 & 20 & $3 S$ & $23-51$ \\
\hline
\end{tabular}


Table 2 Efficiency calculations for the isolation of $\mathbf{3 G ^ { \prime }}, \mathbf{3} \mathbf{S}^{\prime}, \mathbf{4} \mathbf{G}^{\prime}, \mathbf{4} \mathbf{S}^{\prime}$ from industrial pine and hybrid plane

\begin{tabular}{|c|c|c|c|c|c|c|c|}
\hline Species & $\begin{array}{l}\text { Formacell lignin } \\
\text { from wood }^{a} \\
(\mathrm{wt} \% \text { per wood wt) }\end{array}$ & $\begin{array}{l}\text { Silylated mono- } \\
\text { aromatic product } \\
\text { (wt } \% \text { per lignin wt) }\end{array}$ & $\begin{array}{l}\text { Isolated silylated } \\
\text { mono-aromatic product } \\
\text { (wt\% per lignin wt) }\end{array}$ & $\begin{array}{l}\text { Isolated mono- } \\
\text { aromatic product } \\
(\mathrm{wt} \% \text { per lignin } \mathrm{wt})\end{array}$ & $\begin{array}{l}\text { Isolated mono- } \\
\text { aromatic product }^{d} \\
(\mathrm{wt} \% \text { per wood } \mathrm{wt})\end{array}$ & $\begin{array}{l}\text { Theoritical } \\
\text { yield }{ }^{e}(\mathrm{wt} \% \\
\text { per wood wt) }\end{array}$ & $\begin{array}{l}\text { Global } \\
\text { efficiency } \\
(\%)\end{array}$ \\
\hline Industrial & $8(32)$ & 4G $52(43)$ & 4G $36^{f}(70)$ & $\mathbf{4 G}^{\prime} 10^{f}(84)$ & $\mathbf{4 G}^{\prime} 0.8^{f}$ & 9.9 & $8.1^{f}$ \\
\hline pine & $8(32)$ & 3G $25(28)$ & 3G 19 (76) & $\mathbf{3 G}^{\prime} 7$ (86) & $3 G^{\prime} 0.5$ & 8.9 & 5.6 \\
\hline Hybrid & $10(40)$ & 4S 111 (85) & 4S 90 (81) & $\mathbf{4 S}^{\prime} 24$ (94) & $\mathbf{4 S}^{\prime} 2.4$ & 9.4 & 25.5 \\
\hline plane & $10(40)$ & $3 S 45$ (43) & 3S $32^{f^{\prime}}(70)$ & $3 \mathbf{S}^{\prime} 9^{f}(82)$ & $3 \mathbf{S}^{\prime} 0.9^{f}$ & 8.5 & $10.6^{f}$ \\
\hline
\end{tabular}

${ }^{a}$ Weight percentage of lignin extracted using the Formacell process calculated relatively to the wood initial weight (wt\%). ${ }^{b}$ Weight percentage of the silylated products calculated relatively to the initial lignin weight (wt\%). ${ }^{c}$ Weight percentage of the hydrolysed products calculated relatively to the lignin initial weight (wt\%). ${ }^{d}$ Weight percentage of the hydrolysed product calculated relatively to the initial wood weight (wt\%). ${ }^{e}$ Theoretical weight percentage of the hydrolysed product calculated relatively to the initial wood weight (wt\%) and considering that lignin constitutes $25 \mathrm{wt} \%$ of the total wood weight. ${ }^{f}$ Estimated yield (70\% efficiency). The values in brackets correspond to the calculated efficiencies of the steps.

molecular level. These results finally show that the depolymerization methodology described herein is able to selectively yield mono-aromatic products by reductive cleavage of the $\beta-\mathrm{O}-4$ and $\alpha$-O-4 linkages, at room temperature under metal-free conditions. Nevertheless, the application of this strategy to the large scale transformation of lignin might suffer from practical limitations, which derive from the cost of the boron catalyst and the use of stoichiometric amounts of hydrosilanes. The search for cost efficient reduction catalysts and the use of renewable sources of hydrides, such as molecular hydrogen or formic acid, will guide future efforts devoted to improving the sustainability and efficiency of the method. Additionally, replacement of $\mathrm{CH}_{2} \mathrm{Cl}_{2}$ with a greener solvent is desirable. In this respect, the compatibility of benzene with the hydrosilane $-\mathrm{B}\left(\mathrm{C}_{6} \mathrm{~F}_{5}\right)_{3}$ system (see ESI $\dagger$ ) indicates that aromatic solvents are attractive alternative in this technology.

\section{Conclusions}

In summary, we have reported herein the first examples of reductive depolymerization of lignin under metal-free conditions. The reaction is carried out under mild conditions, i.e. ambient pressure and temperature, thereby preventing a problematic re-polymerization of the products via $\mathrm{C}-\mathrm{C}$ bond formation. Labelling studies show that the depolymerization of lignin follows the mechanism unveiled for the hydrosilylation of lignin models and relies on the selective reductive cleavage of the $\beta-\mathrm{O}-4$ and $\alpha$-O-4 linkages in the lignin chain. The versatility of the approach is demonstrated by the successful depolymerization of different lignin preparations, derived from 15 gymnosperms and angiosperms species. For the first time, several different aromatic products can thus be isolated selectively from wood, by tuning the catalytic conditions and selecting the wood source and the lignin extraction method. The methodology indeed yields a narrow distribution of low molecular mass products containing essentially one or two mono-aromatic products (together with longer oligomers), which are easily separable using chromatography, distillation and/or crystallization. The resulting phenol derivatives, e.g. 5-(3-hydroxypropyl)benzene-1,2,3triol and 4-propylbenzene-1,2-diol, were isolated in 7-24 wt\% yield from lignin and $0.5-2.4 \mathrm{wt} \%$ yield from wood. The global efficiency of the process ranges from 5 to $25 \%$. Current efforts are devoted to increase this performance by optimizing the extraction method of lignin and designing novel catalysts with enhanced activity. In this respect, other benign processes causing minimal disruption to the lignin structure will be considered, ${ }^{76}$ such as the steam explosion and ammonia freeze explosion (AFEX) processes. ${ }^{77,78}$ Additionally, genetically modified species containing exclusively one type of residue ( $\mathrm{H}, \mathrm{G}$ or S) linked through $\beta-\mathrm{O}-4$ and $\alpha-\mathrm{O}-4$ linkages could significantly increase the yield and facilitate the purification of the final phenolic product.

\section{Materials and methods}

\section{Extraction of lignin from wood sawdust using a Formacell process}

The extraction was carried out in a $500 \mathrm{~mL}$ round-bottom flask equipped with a magnetic stir bar and a reflux condenser. A total of $15 \mathrm{~g}$ of sawdust was used for each test, applying a ratio of liquor to solid of $\mathrm{L} / \mathrm{S}: 10.0 / 0.83$. The cooking liquor is a mixture of formic acid/acetic acid/water in a 30/50/20\% volume ratio. The suspension was heated at $107^{\circ} \mathrm{C}$ for $3 \mathrm{~h}$ (the boiling point of the water/formic acid azeotrope). After cooling the mixture to room temperature, the suspension was filtered under reduced pressure through a porosity 3 frit and the solid was washed twice with $25 \mathrm{~mL}$ of a mixture of the previous formic acid/acetic acid/water mixture. The volatiles were then removed under reduced pressure from the dark colored solution (in most cases brown) containing lignin and the hemicellulose derivatives. Addition of distilled water $(25 \mathrm{~mL})$ to the solid residue led to the solubilization of the hemicellulose part and precipitation of lignin. The suspension was filtered through a porosity 4 frit and the solid was further washed with water until the washings were colorless. Finally, lignin was dried overnight under primary vacuum. The soluble sugars in the water phase were recovered after removal of water under vacuum. The yields of lignin and hemicellulose derivatives depend on the wood species. The obtained yields are summarized in the $\mathrm{ESI}^{\dagger}$ (Table S1).

\section{Obtaining pure 3G from convergent reductive depolymerization of lignin}

The procedure is detailed for the conversion of lignin (extracted from industrial pine using the Formacell process) to 3G, using $\mathrm{Et}_{3} \mathrm{SiH}$ as the reductant. Nevertheless, Picea abies, Pinus pinea 
and Cedrus libani could be used to obtain the same product with yields ranging from 18 to $25 \mathrm{wt} \%$ and with similar purities.

A $50 \mathrm{~mL}$ round bottom flask equipped with a magnetic stir bar was charged with $400 \mathrm{mg}$ (approximatively $2.0 \mathrm{mmol}$ ) of lignin, previously extracted from wood (using the Formacell process), and $\mathrm{CH}_{2} \mathrm{Cl}_{2}(2 \mathrm{~mL})$. On the other hand, a mixture of $\mathrm{Et}_{3} \mathrm{SiH}(1220.8 \mathrm{mg}, 10.5 \mathrm{mmol}, 305.2 \mathrm{wt} \%)$ and $\mathrm{B}\left(\mathrm{C}_{6} \mathrm{~F}_{5}\right)_{3}$ (100.0 mg, $0.2 \mathrm{mmol}, 25 \mathrm{wt} \%$ ) in $\mathrm{CH}_{2} \mathrm{Cl}_{2}(2 \mathrm{~mL})$ was added slowly (over $30 \mathrm{~min}$ ), at RT. Methane formation was detected by GC chromatography. After $1 \mathrm{~h}$, the entire solid was dissolved and the solution turned from colorless to brown. Stirring was continued for $19 \mathrm{~h}$ at RT and the reaction was monitored by GC-MS. The solvent was then evaporated under reduced pressure and the crude residue was purified by flash chromatography (using a pentane $/ \mathrm{CH}_{2} \mathrm{Cl}_{2}(8: 2)$ mixture as the eluent). After solvent removal under reduced pressure, 3G was obtained as a pale yellow oil (108.0 mg, $0.3 \mathrm{mmol}, 27 \mathrm{wt} \%)$ that could be further purified by distillation (boiling point: $86^{\circ} \mathrm{C}$ under 6 mbar) or by another column chromatography to give pure $\mathbf{3 G}$ as a colorless oil (76.0 mg, $0.2 \mathrm{mmol}, 19 \mathrm{wt} \%$ ). The purity of the compound was assessed by elemental analysis. Anal. calcd for $\mathrm{C}_{21} \mathrm{H}_{40} \mathrm{O}_{2} \mathrm{Si}_{2}$ (mol. wt. 380.72): C, 66.25; H, 10.59. Found: C, 65.73; H, 10.79.

\section{Typical procedure for the hydrolysis of silylated phenolic compounds}

The procedure for the hydrolysis of silylated phenolic compounds is detailed for compound 3G. To a solution of 3G $(380.7 \mathrm{mg}$; 1.0 mmol, 1 equiv.) in $4 \mathrm{~mL}$ of THF $n$ - $\mathrm{Bu}_{4} \mathrm{NF} \cdot 3 \mathrm{H}_{2} \mathrm{O}(315.5 \mathrm{mg}$; $2.1 \mathrm{mmol}, 2.1$ equiv.) was added slowly, under argon and the solution was stirred for $1 \mathrm{~h}$ at room temperature. The volatiles were then removed under vacuum and $4 \mathrm{~mL}$ of dichloromethane was added. Afterwards, the solution was column chromatographed on silica gel using a gradient mixture of dichloromethane and ethyl acetate as the eluent (gradient starting from (100\% dichloromethane to $3: 7$ dichloromethane/ethylacetate)) to afford $\mathbf{3 G}^{\prime}$ (141.5 mg; $0.9 \mathrm{mmol} ; 84 \%$ ) as a colorless oil.

\section{Funding sources}

The present work is supported by the Nuclear Energy Division at CEA (Syndiese program), CEA, CNRS, ERC and the French Academy of Sciences.

\section{Acknowledgements}

For support of this work, we acknowledge CEA, CNRS, Labex CHARMMMAT and ERC (Starting Grant Agreement n.336467). T.C. thanks the Foundation Louis D. - Institut de France for its support. The authors thank K. Feghali, E. Daou, E. Dib, E. Hachach, G. Barbolosi, N. Arrighi, C. Mouawad, W. Choujaa, F. Gharios, R. Feghali, J. Estephan, P. Akoury, P. Saliba, M. Feghali, G. Daou, E. Dib, S. Donck, S. Perato, C. Taglang, G. Pieters, D. Buisson, G. Huber, G. Lefèvre, J.-C. Berthet, M. Ephritikhine, and O. A. Bdadoun for providing wood samples and for fruitful discussions.

\section{References}

1 J. S. Luterbacher, D. Martin Alonso and J. A. Dumesic, Green Chem., 2014, 16, 4816-4838.

2 H. L. Chum and R. P. Overend, Fuel Process. Technol., 2001, 71, 187-195.

3 H. B. Goyal, D. Seal and R. C. Saxena, Renewable Sustainable Energy Rev., 2008, 12, 504-517.

4 P. Fornasiero and M. Graziani, Renewable Resources and Renewable Energy: A Global Challenge, CRC Press Taylor and Francis Group, 2nd edn, 2012.

5 C. Lin, R. Luque, G. Kraus and Y. Kou, Renewable Resources for Biorefineries, The Royal Society of Chemistry, 2014.

6 M. N. Belgacem and A. Gandini, Monomers, Polymers and Composites from Renewable Resources, Elsevier Ltd, 1st edn, 2008.

7 P. Gallezot, Chem. Soc. Rev., 2012, 41, 1538-1558.

8 A. Tlili, E. Blondiaux, X. Frogneux and T. Cantat, Green Chem., 2015, 17, 157-168.

9 J. Albo, M. Alvarez-Guerra, P. Castano and A. Irabien, Green Chem., 2015, 17, 2304-2324.

10 J. Qiao, Y. Liu, F. Hong and J. Zhang, Chem. Soc. Rev., 2014, 43, 631-675.

11 G. Fiorani, W. Guo and A. W. Kleij, Green Chem., 2015, 17, 1375-1389.

12 Q. Liu, L. Wu, R. Jackstell and M. Beller, Nat. Commun., 2015, 6, DOI: 10.1038/ncomms6933.

13 F. G. Calvo-Flores and J. A. Dobado, ChemSusChem, 2010, 3, 1227-1235.

14 B. M. Weckhuysen, ChemSusChem, 2013, 6, 1559-1563.

15 J. Zakzeski, P. C. A. Bruijnincx, A. L. Jongerius and B. M. Weckhuysen, Chem. Rev., 2010, 110, 3552-3599.

16 A. J. Ragauskas, G. T. Beckham, M. J. Biddy, R. Chandra, F. Chen, M. F. Davis, B. H. Davison, R. A. Dixon, P. Gilna, M. Keller, P. Langan, A. K. Naskar, J. N. Saddler, T. J. Tschaplinski, G. A. Tuskan and C. E. Wyman, Science, 2014, 344, 6185.

17 M. P. Pandey and C. S. Kim, Chem. Eng. Technol., 2011, 34, 29-41.

18 R. Vanholme, B. Demedts, K. Morreel, J. Ralph and W. Boerjan, Plant Physiol., 2010, 153, 895-905.

19 S. Y. Lin and C. W. Dence, Methods in Lignin Chemistry, Springer, Berlin, Heidelberg, 1992.

20 H. Hatakeyama and T. Hatakeyama, in Biopolymers, ed. A. Abe, K. Dusek and S. Kobayashi, Springer, Berlin, Heidelberg, 2010, ch. 12, vol. 232, pp. 1-63.

21 H. d. S. Abreu, A. M. d. Nascimento and M. A. Maria, Wood Fiber Sci., 1999, 31, 426-433.

22 W. Boerjan, J. Ralph and M. Baucher, Annu. Rev. Plant Biol., 2003, 54, 519-546.

23 M. S. Singhvi, S. Chaudhari and D. V. Gokhale, RSC Adv., 2014, 4, 8271-8277.

24 R. B. Santos, P. W. Hart, H. Jameel and H. Chang, BioResources, 2013, 8, 1456.

25 H. Wang, M. Tucker and Y. Ji, J. Appl. Chem., 2013, 9, 2013.

26 G. Chatel and R. D. Rogers, ACS Sustainable Chem. Eng., 2014, 2, 322-339. 
27 C. Xu, R. A. D. Arancon, J. Labidi and R. Luque, Chem. Soc. Rev., 2014, 43, 7485-7500.

28 A. Rahimi, A. Ulbrich, J. J. Coon and S. S. Stahl, Nature, 2014, 515, 249-252.

29 M. Zaheer and R. Kempe, ACS Catal., 2015, 1675-1684, DOI: 10.1021/cs501498f.

30 Q. Bu, H. Lei, A. H. Zacher, L. Wang, S. Ren, J. Liang, Y. Wei, Y. Liu, J. Tang, Q. Zhang and R. Ruan, Bioresour. Technol., 2012, 124, 470-477.

31 C. S. Lancefield, O. S. Ojo, F. Tran and N. J. Westwood, Angew. Chem., 2015, 127, 260-264.

32 Q. Song, F. Wang, J. Cai, Y. Wang, J. Zhang, W. Yu and J. Xu, Energy Environ. Sci., 2013, 6, 994-1007.

33 P. J. Deuss, K. Barta and J. G. de Vries, Catal. Sci. Technol., 2014, 4, 1174-1196.

34 P. J. Deuss and K. Barta, Coord. Chem. Rev., 2015, DOI: 10.1016/j.ccr.2015.02.004.

35 J. M. Nichols, L. M. Bishop, R. G. Bergman and J. A. Ellman, J. Am. Chem. Soc., 2010, 132, 12554-12555.

36 S. C. Chmely, S. Kim, P. N. Ciesielski, G. Jiménez-Osés, R. S. Paton and G. T. Beckham, ACS Catal., 2013, 3, 963-974.

37 A. Wu, B. O. Patrick, E. Chung and B. R. James, Dalton Trans., 2012, 41, 11093-11106.

38 T. vom Stein, T. Weigand, C. Merkens, J. Klankermayer and W. Leitner, ChemCatChem, 2013, 5, 439-441.

39 D. Weickmann and B. Plietker, ChemCatChem, 2013, 5, 2170-2173.

40 A. G. Sergeev and J. F. Hartwig, Science, 2011, 332, 439-443.

41 P. Kelley, S. Lin, G. Edouard, M. W. Day and T. Agapie, J. Am. Chem. Soc., 2012, 134, 5480-5483.

42 B. S. Samant and G. W. Kabalka, Chem. Commun., 2012, 48, 8658-8660.

43 M. Nagy, K. David, G. J. P. Britovsek and A. J. Ragauskas, Holzforschung, 2009, 63, 513.

44 A. K. Roy, in Adv. Organomet. Chem., ed. A. F. H. Robert West and J. F. Mark, Academic Press, 2007, vol. 55, pp. 1-59.

45 M. Oestreich, J. Hermeke and J. Mohr, Chem. Soc. Rev., 2015, 44, 2202-2220.

46 J. Y. Corey, Chem. Rev., 2011, 111, 863-1071.

47 V. Gevorgyan, J.-X. Liu, M. Rubin, S. Benson and Y. Yamamoto, Tetrahedron Lett., 1999, 40, 8919-8922.

48 V. Gevorgyan, M. Rubin, S. Benson, J.-X. Liu and Y. Yamamoto, J. Org. Chem., 2000, 65, 6179-6186.

49 V. Gevorgyan, M. Rubin, J.-X. Liu and Y. Yamamoto, J. Org. Chem., 2001, 66, 1672-1675.

50 D. J. Parks, J. M. Blackwell and W. E. Piers, J. Org. Chem., 2000, 65, 3090-3098.

51 D. J. Parks and W. E. Piers, J. Am. Chem. Soc., 1996, 118, 9440-9441.

52 R. D. Nimmagadda and C. McRae, Tetrahedron Lett., 2006, 47, 5755-5758.
53 E. Feghali and T. Cantat, ChemSusChem, 2015, 8, 980-984.

54 E. Blondiaux and T. Cantat, Chem. Commun., 2014, 50, 9349-9352.

55 E. Feghali, O. Jacquet, P. Thuery and T. Cantat, Catal. Sci. Technol., 2014, 4, 2230-2234.

56 E. Feghali and T. Cantat, Chem. Commun., 2014, 50, 862-865.

57 X. F. Sun, R. C. Sun, P. Fowler and M. S. Baird, Carbohydr. Polym., 2004, 55, 379-391.

58 L. Kham, Y. Le Bigot, M. Delmas and G. Avignon, Ind. Crops Prod., 2005, 21, 9-15.

59 C. Chen, in Wood Structure and Composition, ed. M. Lewin and I. S. Goldstein, CRC Press, Boca Raton, 1991, pp. 183-261.

60 W. G. Glasser and H. R. Glasser, Pap. Puu, 1981, 63, 71.

61 M. Erickson, S. Larsson and G. E. Miksche, Acta Chem. Scand., 1973, 27, 903-914.

62 D. W. Tedder, in Albright's Chemical Engineering Handbook, ed. L. Albright, CRC Press, Boca Raton, 2008, ch. 10.

63 J. B. Lindsey and B. Tollens, Liebigs Ann. Chem., 1892, 267, 341-366.

64 T. Voitl and P. Rudolf von Rohr, ChemSusChem, 2008, 1, 763-769.

65 J. Zhang, Y. Chen and M. A. Brook, ACS Sustainable Chem. Eng., 2014, 2, 1983-1991.

66 E. S. Krol and J. L. Bolton, Chem.-Biol. Interact., 1997, 104, 11-27.

67 A. Huboux, J. M. Gaudin, P. Millet and F. Robvieux, Benzodioxole derivatives as watery odorants, WO2012045646A1, 2013.

68 J. Kang, Z. Xijun and T. Qiufeng, Substituted benzo 1,3-dioxygen pentacyclic ring derivative, preparing process and uses thereof, CN 1504468 A, 2004.

69 F. P. Petrocellia and M. T. Kleina, Fuel Sci. Technol. Int., 1987, 5, 25-62.

70 T. H. Parsell, B. C. Owen, I. Klein, T. M. Jarrell, C. L. Marcum, L. J. Haupert, L. M. Amundson, H. I. Kenttamaa, F. Ribeiro, J. T. Miller and M. M. Abu-Omar, Chem. Sci., 2013, 4, 806-813.

71 P. Ferrini and R. Rinaldi, Angew. Chem., Int. Ed., 2014, 53, 8634-8639.

72 S. Camarero, P. Bocchini, G. C. Galletti and A. T. Martínez, Rapid Commun. Mass Spectrom., 1999, 13, 630-636.

73 P. C. Pinto, D. V. Evtuguin and C. P. Neto, Ind. Eng. Chem. Res., 2005, 44, 9777-9784.

$74 \mathrm{H}$. Evju, Ultrafiltration and oxidation of a lignin containing waste sulfite liquor, U.S. Pat., 4,151,207., 1979.

75 T. J. McDonough, Tappi J., 1993, 76, 186-193.

76 M. J. Taherzadeh and K. Karimi, Int. J. Mol. Sci., 2008, 9, 1621-1651.

77 J. Li, G. Henriksson and G. Gellerstedt, Bioresour. Technol., 2007, 98, 3061-3068.

78 M. Holtzapple, J.-H. Jun, G. Ashok, S. Patibandla and B. Dale, Appl. Biochem. Biotechnol., 1991, 28-29, 59-74. 